\title{
IMPACTOS SOCIOAMBIENTAIS NO RIO PARAGUAI, CÁCERES, MATO GROSSO, BRASIL - PERCEPÇÃO DOS PESCADORES DA COLÔNIA Z - 2
}

\section{Social and environmental impacts in the Paraguai River Cáceres, Mato Grosso, Brazil - fishermen's perceptions of the Colony $z$ - 2}

Darci Ordonio dos Santos Bezerra ${ }^{1}$ Haydee Torres de Oliveira ${ }^{2}$

Resumo: Este artigo trata da análise da percepção dos pescadores cadastrados na Colônia Z-2 sobre os impactos socioambientais associados à degradação do rio Paraguai, na zona urbana de Cáceres, Mato Grosso, Brasil. Foram realizadas entrevistas semiestruturadas para o levantamento das percepções dos pescadores e a interpretação dessas respostas. Com base na interpretação da percepção ambiental dos entrevistados, observa-se que os impactos citados provocam: mudanças nas margens do rio, na biodiversidade e no estoque pesqueiro; o assoreamento do leito do rio provocado pelo desmatamento das margens para atividade agropecuária; erosão das margens causada pelo movimento de grandes embarcações de turismo e transporte de soja, e o descaso das autoridades. Conclui-se que os profissionais da pesca de Cáceres estão sensibilizados com as ações predatórias no rio Paraguai e apresentam potencial para lutar por uma melhor qualidade de vida quando sugerem um trabalho coletivo que una interesses e coparticipação.

Palavras-chave: Percepção. Degradação ambiental. Rio Paraguai.

Abstract: This article deals with the analysis of the fishermen's perceptions registered in the Z-2 Colony, and the environmental impacts associated with the degradation of the Paraguai River, in the urban zone of Cáceres, Mato Grosso, Brazil. Semi structured interviews were used to survey fishermen's perceptions and the interpretation of these answers has been carried out. From the interpretation of the environmental perception of the interviewees, it is observed that the cited impacts cause changes in the edges of the river, the biodiversity and in the supply for fishing boats. The destruction of the riverbed caused by the deforestation of the edges by farming activity, and the erosion of the edges caused by the movement of great boats of tourists and the transport of soy together with the indifference of the authorities was noted. One concludes that the professional fishermen of Cáceres are sensitive to the predatory actions in the Paraguai River and have potential to fight for a better quality of life when they suggest a collective work that joins interests and co-participation.

Keywords: Perception. Environmental degradation. Paraguai River.

\footnotetext{
${ }^{1}$ Bióloga, doutora em Ecologia e Recursos Naturais. Aposentada. São Carlos, SP, Brasil.

$<$ dosbezerra@hotmail.com>

${ }^{2}$ Bióloga, Mestre em Ecologia, Doutora em Ciências da Engenharia Ambiental. Docente, Programa de PósGraduação em Ecologia e Recursos Naturais (PPGERN, UFSCar). São Carlos, SP, Brasil. <haydee@ufscar.br>

${ }^{1}$ Rua Fortaleza, 260

Jardim Paulista - Cuiabá, MT

$78.065-350$ 
Bezerra, D. O. S.; Oliveira, H. T.

\section{Introdução}

Neste artigo discute-se a importância da percepção que os indivíduos possuem sobre o ambiente onde estão inseridos. A partir disto, procura-se mostrar que esses dados obtidos por meio de entrevistas semiestruturadas e abertas podem servir de subsídio para a elaboração e execução de programas com atividades práticas de Educação Ambiental, que levem à reflexão crítica da realidade, contribuindo para uma discussão científica dos objetivos da educação, bem como auxiliar a execução de plano de manejo adequado. É importante salientar que o grupo trabalhado foi constituído de pessoas que se utilizam da pesca como meio de subsistência na comunidade cacerense, e que aceitaram discutir os seus problemas coletivos.

A pesca tem grande importância para a população de Cáceres-MT, pois é a base econômica para muitas famílias de baixa renda que utilizam as águas do Alto Paraguai, portal do Pantanal Mato-grossense. A Colônia de Pescadores Z-2 de Cáceres-MT foi criada através da Portaria n 046 da Confederação Nacional dos Pescadores, em 03 de junho de 1982, estando situada às margens do Alto Paraguai, na zona urbana da cidade de Cáceres. A Colônia conta com 450 associados que enfrentam várias dificuldades no seu cotidiano, por não terem os seus direitos respeitados e por não conhecerem, de forma efetiva, o que podem e devem reivindicar.

O ambiente estudado possui características de diversas ações predatórias relacionadas à pesca esportiva e profissional, apresentando, como consequências, impactos socioambientais que afetam diretamente a biodiversidade e o estoque pesqueiro, além da exclusão do profissional da pesca cadastrado na Colônia nas discussões sobre a conservação do rio Paraguai (MEDEIROS, 1999; MARTINS, 2003; LIMA, 2004; LUIZ NETTO, 2001; 2006; SILVA et al., 2007).

Whyte (1978) indica como objetivos da investigação da percepção das populações que interagem com o ambiente:

- a contribuição para utilização mais racional da biosfera;

- o incentivo da participação local no desenvolvimento e planejamento, tendo em vista a realização mais eficiente de uma transformação mais apropriada;

- o aumento da compreensão das bases das diferentes percepções do ambiente;

- o resgate do registro para preservar as percepções e os sistemas de conhecimento do ambiente, que estão em vias de desaparecimento rápido em muitas zonas rurais;

- a ação comunitária como instrumento educativo e de evolução.

Tratar de percepção ambiental é considerar a relação do ser humano com o mundo. Há diversas formas de se perceber o mundo, desde aquela revestida com o manto da sacralização, até aquela ancorada no arcabouço cientificista dominador. Essas formas se revelaram, ao longo da história do pensamento humano, no meio da diversidade das diferentes civilizações (MARIN, 2003).

Para a população humana, a água se inscreve no domínio do simbólico, enfeixando várias imagens e significados. A imagem das águas é manifestada: nas cerimônias sagradas e mitológicas, nos rituais, nas formas diversas de manejo de solos, no cultivo de plantas, enfim, o significado das águas é múltiplo (CUNHA, 2000). A imagem e os símbolos, construídos pelas comunidades tradicionais, são cercados de lendas, músicas, linguagens específicas e contos que expressam a vida, o cotidiano, as alegrias e tristezas, as perdas e os ganhos (DIE- 
Impactos socioambientais no Rio Paraguai ...

GUES, 2000). Elas refletem, também, mudanças sociais e culturais diante da expansão urbana e turística na beira dos rios e lagoas e nas regiões costeiras.

Para o pescador, a sua profissão é privilegiada; o seu trabalho não é agitado, o pescador reflete o silêncio das águas [...] chuva e água, sol e água, noite e água. Pode faltar o peixe, pode faltar a rede, mas nunca este contato direto com a natureza: sol-chuva-noite-água (LABERGE, 2000). A água é ainda motivo de inspiração para os poetas:

Ela assimila tantas substâncias! Tantas essências! Recebe com igual facilidade as matérias contrárias, o açúcar e o sal. Impregna-se de todas as cores, de todos os sabores, de todos os cheiros [...] a água clara é uma tentação constante para o simbolismo fácil da pureza onde os seres humanos encontram essa imagem natural. (BACHELARD, 2002, p. 96)

\section{Conceituando percepção}

Podemos considerar que a soma das atividades econômicas, sociais e culturais determina o estilo de vida de um povo. Estas atividades geram padrões espaciais; requerem formas arquitetônicas e ambientes materiais que, por sua vez, após terminados, influenciam o padrão das atividades (TUAN, 1980). Compreendemos o estilo de vida de um povo, a sua atitude em relação ao mundo a partir da evidência acumulada dos atos diários e do caráter das circunstâncias físicas onde ocorrem. E isto é evidenciado na fala dos entrevistados quando questionados sobre como percebem o meio ambiente.

Iniciamos a nossa discussão sobre percepção voltando o nosso olhar para a relação, apontada por Forgus (1971), entre percepção, aprendizagem e pensamento. Para ele, a percepção é o "processo pelo qual um organismo recebe e extrai informações acerca do ambiente." A aprendizagem, quando "esta informação é adquirida através da experiência e se torna parte do armazenamento de fatos do organismo." E, finalmente, o pensamento "é uma atividade cuja ocorrência se infere quando um organismo está ocupado em resolver problemas, o que também envolve o emprego de modelos" (FORGUS, 1971, p. 3). Servimo-nos das ideias do autor para destacar a importância do pesquisador em conhecer a percepção das pessoas com quem está trabalhando.

Os estímulos possuem informação que é extraída pelo organismo sob a forma de aprendizagem. Esta aprendizagem modifica o organismo de modo que a percepção posterior dos mesmos estímulos será diferente. O processo de pensamento (resultante de aprendizagem prévia) também modifica o organismo porque ocorre nova aprendizagem; assim é que a percepção de estímulos sofre modificação. (FORGUS, 1971, p. 5)

A maior parte das atividades do sistema nervoso tem início com a experiência sensorial derivada dos receptores sensoriais (visuais, auditivos, táteis etc.).

Para Davies, Blakeley e Kidd (2002, p. 245), 
[...] esta experiência sensorial tanto pode provocar uma reação imediata, como pode ser armazenada como memória no encéfalo por minutos, semanas ou anos, capacitando-se a auxiliar na determinação das reações corporais numa oportunidade futura.

A informação sensorial é essencial para nossa capacidade de responder ao ambiente externo ou ao estado interno do corpo. Em sua maior parte, a sensação externa é experienciada conscientemente, embora também seja usada em níveis subconscientes.

Grande parte da informação sensorial, sobre o estado interno do corpo, no entanto, não atinge o nível do conhecimento consciente. $O$ ver não é um processo passivo. Exploramos, constantemente, nosso ambiente, com graus variados de atenção.

As percepções sofrem influência das características pessoais, mas também do contexto social, das instituições nas quais a pessoa está integrada:

Assim, segundo os indivíduos, os mesmos objetos, os mesmos acontecimentos, as mesmas pessoas do mundo exterior impõem-se com uma significação diferente. A percepção do mundo é diferente para cada um de nós, cada pessoa percebe um objeto ou uma situação de acordo com os aspectos que têm especial importância para si própria. (DAVIES; BLAKELEY; KIDD, 2002, p. 250)

Para Tuan (1980, p. 12), "percepção é tanto a resposta dos sentidos aos estímulos externos, como a atividade proposital, na qual certos fenômenos são claramente registrados, enquanto outros retrocedem para a sombra ou são bloqueados."

A visão do mundo é a experiência conceitualizada. Ela é parcialmente pessoal, em grande parte social. Duas pessoas não veem a mesma realidade. Nem dois grupos sociais fazem exatamente a mesma avaliação do ambiente. A própria visão científica está ligada à cultura - uma possível perspectiva entre muitas. Ver não envolve profundamente as nossas emoções. "Uma pessoa que simplesmente 'vê' é um espectador, um observador, alguém que não está envolvido com a cena. Um ser humano percebe o mundo simultaneamente através de todos os sentidos. A percepção é uma atividade, um estender-se para o mundo" (TUAN, 1980, p. 12).

Del Rio (1996) afirma que nossa mente organiza e representa essa realidade percebida através de esquemas perceptivos e imagens mentais, com atributos específicos:

Embora essas percepções sejam subjetivas para cada indivíduo, admitese que existam recorrências comuns, sejam em relação às percepções e imagens, sejam em relação às condutas possíveis [...] ao se evitar conflitos de percepção entre os sistemas cognitivos de planejadores, empresários, grupos de usuários e público em geral, a ação ambiental estará sendo direcionada para resultados mais satisfatórios. (DEL RIO, 1996, p. 4)

Uma boa imagem ambiental oferece a seu possuidor um importante sentimento de segurança; pode estabelecer uma relação harmoniosa entre ele e o mundo à sua volta. $\mathrm{Na}$ verdade, um ambiente característico e legível não oferece apenas segurança, mas também 
Impactos socioambientais no Rio Paraguai ...

reforça a profundidade e a intensidade, potenciais da experiência humana. "O observador deve ter um papel ativo na percepção do mundo e uma participação criativa no desenvolvimento de sua imagem. Deve ser capaz de transformar essa imagem de modo a ajustá-la a necessidades variáveis" (LYNCH, 2006, p. 5-6).

\section{Metodologia}

De acordo com as afirmações de Loureiro (2006, p. 132) "o cotidiano do ser humano não é rotina (fazer por fazer e de modo repetitivo), mas o espaço imediato de realização e desenvolvimento do indivíduo". É quase sempre a ação espontânea em decorrência do dia-adia. Refere-se ao lugar habitado e ocupado pelos indivíduos, onde exercitamos nossa cidadania diariamente, mantemos relações com os outros, procuramos a coerência entre desejos, pensamentos e atitudes. "As grandes transformações históricas só se concretizam quando são incorporadas ao modo de vida das pessoas e à sua existência cotidiana, vinculando o particular ao público, o microssocial ao macrossocial”. (LOUREIRO, 2006, p. 132)

Com o objetivo de conhecer a percepção dos pescadores, levou-se em consideração que a cidade de Cáceres cresceu e sempre se desenvolveu mantendo relações com o rio e com a passagem do tempo, entretanto, algumas relações foram diminuindo, outras se deterioraram fortemente e outras, ainda, até desapareceram. Realizou-se uma pesquisa qualitativa, participativa, de acordo com as afirmações de Tozoni-Reis (2006).

Entrevistou-se um grupo de vinte pessoas, no universo de cinquenta daquelas que frequentavam o Curso de Alfabetização Pescando Letras da Secretaria do Estado de Educação de Mato Grosso, oferecido na Colônia Z-2 nos períodos de piracema 2006/2007 e 2007/2008.

Algumas perguntas foram feitas, no entanto, deixou-se o depoimento fluir à vontade, a ponto de algumas entrevistas durarem três a quatro horas de gravação. As categorias selecionadas nas respostas obtidas e interpretadas neste artigo, num total de cinco, dizem respeito: ao cotidiano da pesca no rio Paraguai; à percepção de potencialidades e impactos; às mudanças na biodiversidade e no estoque pesqueiro; ao sentimento topofílico, e às soluções minimizadoras para os problemas ambientais do rio. Outras categorias detectadas nas entrevistas, como o etnoconhecimento, as histórias de vida e os "causos", muito bem relatados, não serão abordadas neste trabalho, permitindo-nos uma análise posterior.

\section{Interpretando a percepção dos pescadores sobre os impactos no rio Paraguai}

\section{O cotidiano da pesca no rio Paraguai}

A importância do rio Paraguai na percepção do pescador está ligada à questão de sobrevivência, enquanto oportunidade de pesca. Por outro lado, considera o rio sua vida, sua existência. Por meio do rio, criaram seus filhos, enfim, é uma fonte de renda e de vida: 
Bezerra, D. O. S.; Oliveira, H. T.

"O rio Paraguai... é o que sobrevivemos da infância até agora na idade nossa ... meu pai criou nós e en já criei meus filhos neste rio Paraguai" (C. J., 51 anos).

O rio, pra mim, é de grande importância, porque ali é que nós tomamos a água, tomamos o banho, dali que molhamos as plantas, afinal é tudo. É a sobrevivência para o pescador... Serve de lazer, a gente vai pescar. Prá se divertir, escutar umas palavras boas. Ai então, é muita coisa importante. (P. M. C., 51 anos)

Observa-se, nos depoimentos dos pescadores, uma grande admiração pelo rio, por fornecer-lhes o sustento da família.

Os lugares são centros aos quais atribuímos valor e onde são satisfeitas as necessidades biológicas de comida, água, descanso e procriação. A partir da segurança e estabilidade do lugar estamos cientes da amplidão, da liberdade e da ameaça do espaço e vice-versa. (TUAN, 1980, p. 127)

São extremamente complexos os sentimentos e as ideias relacionadas com espaço e lugar do ser humano adulto. Originam-se tanto das experiências singulares como das comuns; e, pelo contínuo acréscimo de sentimento ao longo dos anos, o lugar pode adquirir profundo significado para o indivíduo. Quando o espaço nos é inteiramente familiar, torna-se lugar (MACHADO, 1988). Vejamos o que diz L. S. S. de 46 anos:

"Olha, o rio Paraguai é a nossa fonte de renda. É o lugar onde a gente extrai o pescado para a nossa manutenção, da família principalmente. Pra mim o rio tá sendo a fonte de ganbo dos pescadores. Quanto mais preservar é em beneficio da gente, porque é mais tempo prá gente sobreviver."

No mundo moderno, as comunidades pesqueiras, de modo geral, são pobres quando comparadas com comunidades agrícolas no interior; e se elas suportam este modo de viver, não é tanto pela recompensa econômica, senão pelas satisfações obtidas deste estilo de vida ancestral e tradicional (TUAN, 1980), como afirma J. S. F., de 54 anos:

"O rio Paraguai pra mim significa uma grande coisa; faz.parte da minha profissão porque en busco o alimento dele... en convivo dentro dele... ocupo a água dele... isso é a minha vida. É a vida de todo pescador. O meu pão de cada dia é dentro dele. O rio é uma vida. Sabe o que é uma vida? O dia que a gente pode, pega o barco e vai de novo. Esse rio aí, é uma vida! Já pensou eu com 54 anos, ficar sem o rio, vou fazer o que? Pense bem, eu vou fazer o que?"

O visitante e o nativo focalizam aspectos bem diferentes do meio ambiente: "[...] o visitante tem um ponto de vista; sua percepção freqüentemente se reduz a usar os seus olhos para compor quadros" (TUAN, 1980, p. 4-5). Ao contrário, o nativo tem uma atitude complexa derivada da sua imersão na totalidade de seu meio, denominado, por sentimento topofílico, “o elo afetivo entre a pessoa e o lugar ou ambiente físico" (TUAN, 1980, p. 4-5). 


\title{
Percepção de potencialidades e impactos
}

Tonissi (2005, p. 50) afirma que:

\begin{abstract}
A percepção das pessoas que construíram sua história em cada cidade e puderam acompanhar as modificações de origem natural e/ou antrópica ocorridas no local é significativa. Essa experiência de vida pode possibilitar que estes indivíduos reconstituam a história do local, comparem a qualidade ambiental atual com a de outras épocas e relatem com detalhes os processos de degradação responsáveis pelos impactos ambientais atuais e nos oferecer ampla margem de discussão coletiva.
\end{abstract}

Há uma queixa bem fundamentada, tradicionalmente, pelo pescador cacerense de que o peixe está acabando e que a pesca não é mais abundante como em anos anteriores. Alguns atribuem o fato ao desmatamento desenfreado para a formação de pastos: "O que mais incomoda, o que mais tá acabando o peixe pra mim é o desmatamento. É o que tá mais prejudicando. Quem sabe os grandes fazendeiros para produção [...] na minha profissão já é prejudicial porque está assoreando o rio, ta acabando...” (E. K. 42 anos). O entrevistado P. M. C., de 63 anos, afirma:

"Veja bem pra mim que eu conbeci esse rio... hoje en falo pra meus companheiros que o peixe acabou. Eles falam: acabou nada. Acabou. Ali no Morro Pelado, a senhora ia lá, olhava na praia assim e contava peixe até não vencer contar... A hora que o sol vinha saindo assim... a senhora contava tudo naquele lugar mais raso que enxergava água limpa, né?"

No conceito de Ferrara (1996, p. 105):

Cada pessoa percebe seletivamente aquilo que lhe interessa, aquilo que está habituado a observar, de acordo com o seu contexto sociocultural [...] a atividade perceptiva diária enriquece continuamente a experiência individual e por meio dela nos apegamos cada vez mais ao lugar. Cada atitude envolve sempre um conjunto organizado de sentimentos e experiências que influenciam a conduta individual e de grupo [...] a conservação de qualquer meio ambiente é sempre sinônimo de respeito adequado ao patrimônio natural.

Baseados na experiência que demonstram em suas falas, os pescadores afirmam que o assoreamento é um problema muito sério, sobretudo provocado pela destruição das margens pelas embarcações (também conhecidas na região como chatas) que transportam soja:

"Parece que não é nada, mas é porque ta encoberto. Quando a gente viaja lá pra baixo, vez em quando trompa em monte de areia, em lugar que a gente estava acostumado a passar... muda... Quando uma chata dessa engancha, a senhora 
Bezerra, D. O. S.; Oliveira, H. T.

precisa de ver, ele manda de ré, abre o canal tira ela; aquela areia dali ele joga lá no canal e abre o canal." (J. S. F., 67 anos)

As falas dos pescadores entrevistados revelam que a pesca, nos dias atuais, está difícil, especialmente porque eles precisam se deslocar a grandes distâncias, a despesa com combustível e gelo fica descoberta com relação à quantidade de pescado conseguida. Há diversas maneiras de os pescadores perceberem a diminuição dos peixes. Alguns culpam o intenso movimento nas águas do rio provocado pelas grandes embarcações. Segundo J. L. S. (52 anos), o peixe "foge" do barulho causado pelos motores e pelo movimento das águas:

"Muitas e grandes mudanças, principalmente na estrutura do rio. Naquele tempo a navegação, o motor mais potente que tinha aqui era 20-25 HP. Então, isso pouco agredia as barrancas, né? Hoje nós temos aqui motor de 250 HP. Então esses barcos grandes produzem uma onda forte, uma onda grande, essa onda diária está agredindo o barranco. A navegação que existia era navegação de pequeno porte.” (J. L. S., 52 anos)

Há quem afirme que o número de pescadores também está contribuindo para a diminuição do peixe, além da presença de predadores naturais (jacarés e piranhas). Vejamos o que diz J. L. S. de 52 anos:

"Agora, daquele tempo prá cá, houve mudanças significativas na navegação no rio. Isso eu acho que determinou a movimentação, a subida dos cardumes, migração dos cardumes. É... que diminuiu, isso é uma realidade... mas não tanto quanto se propala. É evidente que o cardume vem diminuindo, mas porque a pressão é muito grande. O aumento do pescador em cima do cardume. Tem colaborado prá isso, o assoreamento do rio, jacaré, piranha, pressão da pesca, não só o profissional como se diz aí, popularmente."

Enquanto C. J., de 51 anos, coloca a causa da diminuição do estoque pesqueiro exclusivamente nos jacarés:

"O que tá acabando mais com os peixes é o jacaré. Tem mais de milhão de jacaré no pantanal... tem lugar que você não pode lavar a mão, o jacaré vem em cima. Não é tanto o pescador. Um jacaré prá não comer nada, come cinco quilos de peixe todo o dia. O povo fala que é o pescador que está acabando com o peixe, turista, não é não. Acho que devia combater um pouco de jacaré."

O fato é que todos os entrevistados apresentaram queixas com relação à pesca: o peixe diminuiu, o rio mudou bastante, existe a questão de assoreamento, erosão de barrancas, maior número de pescadores e de embarcações, apropriação das margens, turistas em grande quantidade, como diz L. S. S. (46 anos): 
"Tá dificil porque tá.... os peixes diminuiram muito e aí o custo também para o pescador ir lá e voltar, vender esse peixe, tá sendo mais difícil do que antes. Antes era mais fácil, já saía daqui e já vendia o peixe. Agora, a gente tem que se deslocar para longe e a despesa é grande. Até a quantidade de peixe diminuiu também."

Outros acham que: "Mudou muito ... primeiro, mudou muito o rio ... Nosso percurso do rio mudou muito e mudou os peixes. Aumentou a população, a poluição, o desmatamento, a destruição por causa dos navios" (J. S. F., 57 anos). Para J. L. S., de 52 anos:

"Hoje tem as barcaşas da soja que agridem o barranco diretamente, principalmente nas curvas onde nós os pescadores consideramos que são os lugares que deveriam ser mais protegidas porque cada vez que agridem esse barranco, o barranco cai e vai aterrando... o leito do rio vai assoreando, e o rio vai ficando cada vez. mais largo, porem mais raso, dificultando muito a navegação."

Isso mostra a preocupação em manter o volume e a qualidade desse recurso hídrico em níveis adequados, de modo que atendam às necessidades de toda a população e das gerações futuras, que deverão ter, no mínimo, as mesmas necessidades e direitos que as atuais (MACHADO, 1988). Esses depoimentos revelam sempre a preocupação em proteger, conservar o rio e os peixes, pois as consequências serão catastróficas, como fala J. S. F., de 67 anos:

"Ah! Ai o peixe não sobe mais... o peixe é assim. Ele tem o caminho dele. Sujou o caminho dele, tirou do lugar, ele vem ali e volta. O peixe é tão melindroso... na subida da desova, se tiver um rio estreito como o Jauru, lugar encachoeirado, se eu quiser matar um cardume inteirinho, eu mato, com arame. Então, com essas embarcações, com areia trocando de lugar, praia crescendo, nós vamos ter problema sério."

Todos demonstram preocupação com a conservação do rio Paraguai:

"A barranca... o problema da barranca é quando o rio tá secando, baixando as águas... Ele cheio não tem problema porque a água passa por cima. Agora, quando ele baixa que chega ao nível da caixa dele, ai a embarcação passa, aquela onda vai no barranco e bate." (V. T. A., 45 anos)

\section{Sentimento topofílico}

O entrevistado J. S. F., de 67 anos, conta como viu a mata ser destruída, e teme pelo que possa acontecer no rio Paraguai. É um alerta que deve ser levado em consideração:

"Desse jeito que ta aí, eu não sei, porque o que eu vi é o que aconteceu com a nossa mata. Acabou. Até 78, a gente tinha muita mata em Mato Grosso. Eu vi passar veneno e depois botavam fogo. Passava veneno de avião. Não acabou? A mata 
Ele percebe risco ambiental.

Kates (1978) apud Poltroniéri (1996, p. 241) define risco ambiental "como uma ameaça potencial apresentada ao homem ou à natureza por eventos originados ou transmitidos ao meio ambiente natural ou construído".

A percepção dos riscos ambientais constitui um dos temas que vêm sendo investigados no campo da percepção do meio ambiente. Poltroniéri (1996) enfatiza a percepção dos riscos e as tomadas de decisão, ou seja, as respostas humanas aos riscos, no nível individual e comunitário:

As respostas humanas aos riscos ambientais são elaboradas por meio de ajustamentos e adaptações, procurando superar os efeitos negativos dos riscos e ocorrem em função de níveis ou limiares (do conhecimento, da ação e da intolerância), os quais variam de sociedade para sociedade em função das diferenças de percepção individual e de grupo. Ao atingir o limiar de intolerância passa-se a perceber o risco ambiental como intolerável e as atitudes são alteradas, procurando-se meios alternativos. (POLTRONIÉRI, 1996, p. 241)

Sauvé (2005) lembra a questão da Educação Ambiental para o Desenvolvimento Sustentável - EADS, que nos remete à reflexão: deveríamos ouvir as vozes desses pescadores que presenciaram, ao longo dos tempos, verdadeiras atrocidades no ambiente pantaneiro, na direção da insustentabilidade socioambiental.

É importante observar a origem da apropriação de um espaço e o seu enraizamento, que é um processo que se dá em longo prazo, à medida que a pessoa ou grupo convive, reflete, compreende a importância, se identifica e transforma o espaço em lugar. Esse processo de apropriação é construído a partir das mudanças ocorridas no próprio indivíduo ou grupo e, no momento em que este começa a se identificar com o espaço-agora-lugar sente o desejo-responsabilidade e a capacidade-propriedade para dele cuidar. (TONISSI, 2005, p. 45-46)

O pescador M. S., de sessenta anos, comprova o sentimento de paz que sente navegando pelas águas do rio Paraguai:

'Pra mim eu não sei se vou falar uma coisa certa, mas quando eu estou no rio é uma tranqüilidade. Paq. Quando a gente está no rio, tá tranqüilo. Tem água, abundância. O ar lá parece que é mais gostoso. O que eu gosto mais do rio é a paz. e a tranqüilidade. Pescando, chega a hora que quer, não quer pescar mais, vem para o acampamento, faz a comida e come. É um alivio!” 
Impactos socioambientais no Rio Paraguai ...

\section{Soluções minimizadoras}

Os entrevistados queixaram-se da intensa fiscalização sobre eles e do privilégio dos ricos, como afirma J. P. A., de 52 anos:

"Quando chega a época que fecha a pesca, ai fala que tem a pesca ribeirinha. Isso ai não existe mais, porque não tem nenbum pobre que sobrevive de peixe, morando na beira do rio. Quando chega essa época, é lazer do rico, porque eles têm mansão na beira do rio, ai vem todos os parentes deles pra cá. Ai, chega ali e vai pescar; eles são considerados ribeirinhos, podem pescar à vontade, por que?"

Durante as entrevistas, observou-se que os pescadores falam do rigor das autoridades fiscalizadoras em relação aos profissionais da pesca, ao mesmo tempo em que facilitam as atividades irregulares dos turistas e de outros usuários do rio que moram em Cáceres. Na zona urbana da cidade pode-se encontrar grande número de residências de alto padrão, de propriedade dos empresários e das autoridades locais. Muitas delas foram construídas sem considerar as normas estipuladas para as margens de rio. Loureiro (2006) afirma que:

Nas sociedades contemporâneas o trabalho cerebral daqueles que detêm os meios de produção e as elites intelectuais é valorizado e associado à racionalidade e ao espírito; e o trabalho braçal dos expropriados e dos trabalhadores assalariados é desvalorizado e associado aos elementos intuitivos, instintivos, e às partes 'menos nobres' do ser físico - braços, pernas, ouvidos, olhos etc. O corpo deixa de ser um todo físico, mental e espiritual e passa a ser um objeto privilegiado para o exercício da dominação. (LOUREIRO, 2006, p. 134)

Em seus depoimentos, falam que não têm voz para reivindicar, por ocasião das reuniões de que participam com as autoridades da pesca e órgãos fiscalizadores:

"Eu já me sinto aborrecido, sinceramente, a gente não tem direito a nada. Esses dias, já tive falando pra uma fiscal da SEMA: vocês cobram quanto querem, o pescador está sempre errado, vocês fazem um monte de coisa. Por que vocês estão pescando só peixinho? Por que vocês não pescam peixe grande?” (J. P. A., 52 anos)

O pescador J. S. F., de 57 anos, acrescenta:

"As autoridades daqui ainda não entenderam que o maior fiscal do rio somos nós. No dia que eles entenderem isso, ai nosso rio será preservado. Pra se preservar aquele peixe que tem lá, o pirarucu, eles podiam fazer aqui com nós. Quem botou rede não recebe salário desemprego, nem pode vender o peixe. Lá, quem pescou o pirarucu na comunidade, fica 1 ano sem vender." 
O entrevistado refere-se aos rios da Região Norte onde ocorre a presença do pirarucu, e faz um paralelo de atuação dos órgãos fiscalizadores, que, se adotassem as mesmas normas no rio Paraguai, seria mais coerente, porque o próprio pescador estaria colaborando e fiscalizando a atividade da pesca.

$\mathrm{Na}$ fala de J. P. A., de 52 anos, percebe-se que a classe dos profissionais da pesca em Cáceres não tem os privilégios das pessoas mais abastadas. As cevas (locais onde há um tratamento especial em termos de alimentação para os peixes) são, geralmente, propriedade de particulares, o que lhes confere maior probabilidade da pesca de espécies nobres, como o pintado (Pseudoplatystoma corruscans), o cachara (Pseudoplatystoma fasciatum) e o pacu (Piaractus mesopotamicus):

"Se a gente sai daqui até a Bela Vista, não vê nenhum pobre morando na beira do rio. É só mansão, hotel e outras coisas. Essas cevas, nada, nada. Eles pegam uma base de uns 200 quilos de peixe por dia. Porque se a gente pegar um peixe fora da medida, e eles chegam e acham, é uma polêmica danada... a gente vai até preso. Mas, se for um rico! Aqui mesmo tem ceva que transporta milhares de peixe para o centro da cidade. A ceva deles é na beira do rio... O que é que eles faz̨em? Pegam o peixe, já tem o secretário ali, o que eles vão pegando, vão guardando no isopor lá no mato. Ai, quando chega a certa quantia ele leva. Não fica na beira do rio; o peixe com medida ele larga na beira do rio e aquele fora de medida, ele leva todinho...” (J. P. A., 52 anos)

Outro ponto importante na fala dos entrevistados foi a ênfase dada sobre os resíduos sólidos deixados à beira do rio pelos turistas e usuários locais, provocando poluição das águas:

"O turista larga a sujeira... é lata de cerveja, é sacola de lixo, papel higiênico. Mas... antigamente vinha caminhão ai na beira do rio, acampava, levava mil quilos, dois mil quilos, dizendo ser turista" (C. J., 51 anos).

"A gente deve evitar poluir. Evitar levar as coisas que podem poluir a água, lixo, derrubada, queimada prá evitar enxurrada de água para o rio. Se cada um tiver cuidado, levar um vasilhame e trazer o lixo de volta, en acho que melhora bastante." (M. S., 60 anos)

Sem a autocompreensão, não podemos esperar por soluções duradouras para os problemas ambientais, que, fundamentalmente, são problemas humanos, e os problemas humanos econômicos, políticos ou sociais dependem do centro psicológico da motivação, dos valores e atitudes que dirigem as energias para os objetivos (TUAN, 1980).

Segundo Loureiro (2006), processos educativos podem e devem ser desencadeados a partir dessa leitura de mundo, uma educação ambiental que tenha como pressuposto fomentar processos emancipatórios, na medida em que:

A preparação dos sujeitos da ação educativa é feita prioritariamente para estes se organizarem e intervirem em processos decisórios nos 
Impactos socioambientais no Rio Paraguai ...

espaços de participação existentes. Educação Ambiental coerentemente articulada com a cidadania, e que pretende servir a um projeto social emancipatório e transformador, em sintonia com os ideais de construção de uma sociedade ecologicamente prudente, socialmente justa, culturalmente diversa, politicamente atuante e economicamente viável. (LOUREIRO, 2006, p. 15-16)

Ferrara (1996, p. 97) acrescenta que:

Cada imagem e idéia sobre o mundo são compostas, portanto, de experiência pessoal, aprendizado, imaginação e memória. Os lugares em que vivemos, aqueles que visitamos e percorremos, os mundos sobre os quais lemos e vemos em trabalhos de arte, e os domínios da imaginação e da fantasia contribuem para as nossas imagens da natureza, de tudo o que o ser humano constrói e dele próprio. Todos os tipos de experiência, desde os mais estreitamente ligados com o nosso mundo diário até aqueles que parecem remotamente distanciados, vêm juntos compor o nosso quadro individual da realidade.

Hoeffel e Fadini (2007, p. 256) enfatizam que "o estudo de percepções sobre o mundo natural torna possível identificar e caracterizar distintas relações ser humano/natureza e pode auxiliar na formulação de políticas públicas que visem ações sustentáveis em longo prazo."

Sendo, deste modo, importante veículo para as reflexões entre ciência e educação como afirma Carvalho (1998, p. 17):

Muitas vezes a crise ambiental é também a crise de um conjunto de relações sociais. Os problemas ambientais denunciam desigualdades profundas no acesso das populações aos recursos da natureza e às boas condições ambientais. As lutas de comunidades em torno de saneamento básico, remoção de depósitos de lixo de áreas densamente povoadas, despoluição de mananciais são alguns exemplos disso.

\section{Considerações finais}

Diante do exposto, considera-se que o profissional da pesca de Cáceres, é dotado de conhecimentos, sabedoria e consciência sobre o seu espaço, dentro de seu contexto. E é influenciado pelo grupo que expressa e reforça padrões culturais da sociedade, o que afeta fortemente a percepção, a atitude e o valor que seus membros atribuem ao meio ambiente.

Percebe os riscos ambientais determinados pela pesca predatória, motivada pelos contatos superficiais com a natureza, como no caso de alguns turistas, que, certamente, pouco têm de autêntico. $\mathrm{O}$ turismo tem uma utilidade social e beneficia a economia, porém, quando não planejado e adequadamente monitorado, pode trazer consequências danosas para o ambiente. 
Fica claro, também, que, em Cáceres, ainda não se chegou a formular um projeto de desenvolvimento, pois as atividades turísticas não se articulam com outras políticas econômicas e socioculturais dentro do município (CASTRILLON; BEZERRA, 2003). Apesar disso, essas atividades articulam setores do empresariado, na sociedade local, com capacidade de expressarem publicamente os seus interesses.

No entanto, ocorre exclusão de setores importantes, como: os pescadores profissionais e de barranco, os vendedores ambulantes, artistas e artesões locais, comerciantes e moradores de bairros periféricos, além de ONGs, movimentos sociais e pesquisadores que questionam investimentos em atividades cujos estudos de impactos socioambientais ainda não foram suficientemente avaliados. A participação da comunidade local deve ser incorporada a qualquer planejamento turístico de uma região, desde o planejamento das atividades até os benefícios resultantes dessa prática.

Observa-se que as queixas dos pescadores estão sempre voltadas para as dificuldades que têm enfrentado na pesca do rio Paraguai, sejam pela presença de muitas pessoas em busca de lazer oferecido pela pesca esportiva, utilizando embarcações com possantes motores, sejam pela degradação do rio (assoreamento, destruição das matas ripárias, transporte de soja, falta de fiscalização adequada).

Nossas percepções do tempo e do espaço têm a ver como nossas atividades e sensibilidade. Esse é o ponto de partida das observações do pesquisador em uma abordagem perceptiva: procurar descobrir a realidade investigada, tal como experienciada pelo sujeito, é procurar resgatar, de modo tão preciso quanto possível, o que ocorre com ele ao viver suas experiências e, desta forma, poder criar espaços de discussão coletiva, captar as sugestões para os problemas detectados e buscar alternativas para contribuir com sua minimização.

A partir da interpretação da percepção ambiental dos entrevistados, considera-se que os profissionais da pesca de Cáceres estão sensibilizados com as ações predatórias que prejudicam a conservação do rio Paraguai; apontam para uma série de causas; queixam-se que não têm voz para reivindicar os seus direitos, e apresentam potencial para lutar por uma melhor qualidade de vida quando contribuem para a minimização dos problemas, sugerindo um trabalho coletivo que une interesses e coparticipação.

As discussões efetuadas junto aos pescadores permitiram a elaboração de propostas de educação ambiental, realizadas em etapa posterior.

Reconhecemos, portanto, que os pescadores percebem as atividades causadoras de impactos negativos no rio Paraguai, e apontam soluções viáveis, discutidas coletivamente, que poderiam ser levadas em consideração pelos governantes.

De acordo com as discussões efetuadas com o grupo entrevistado, respeitando-se o saber popular dos pescadores, que muito nos ensina e orienta, pode-se chegar a uma síntese dos resultados, representados no Quadro 1.

Observamos que todos eles apontam atividades predatórias, como: transporte de soja (via rio), barcos com motores possantes, desmatamento das margens para agropecuária, construções civis nas margens do rio, despejo de esgoto "in natura”, presença de resíduos sólidos, entre outras, causadoras de impactos ambientais - tais como erosão das margens, destruição da vegetação, desequilíbrio na cadeia alimentar, alteração do estoque pesqueiro, comprometimento da qualidade da água, do ar e do solo. 
Impactos socioambientais no Rio Paraguai ...

Um dos pontos mais importantes da pesquisa foi o momento em que todos os entrevistados, de uma maneira ou de outra, sugeriram medidas alternativas e solucionadoras para a melhoria da conservação do rio Paraguai, o que confere cientificidade nos dados coletados e interpretados, tendo em vista que não estávamos calcados em nossas certezas, mas abertos ao diálogo.

Quadro 1. Percepção de impactos e soluções levantadas pelos pescadores.

\begin{tabular}{|c|c|c|}
\hline Atividade & Impacto & Solução sugerida \\
\hline Transporte de soja (via rio) & Erosão das margens & Apoio dos órgãos governamentais \\
\hline Barcos com motores possantes & Destruição da vegetação & Garantia de espaço nas discussões \\
\hline $\begin{array}{l}\text { Desmatamento das margens para a } \\
\text { agropecuária }\end{array}$ & Desequilíbrio na cadeia alimentar & Apoio dos órgãos governamentais \\
\hline $\begin{array}{l}\text { Construções civis nas margens do rio } \\
\text { Despejo de esgoto"in natura" }\end{array}$ & $\begin{array}{l}\text { Alteração do estoque pesqueiro } \\
\text { Comprometimento da qualidade } \\
\text { da água, do ar e do solo }\end{array}$ & Garantia de espaço nas discussões \\
\hline Presença de resíduos sólidos & & Saneamento básico \\
\hline
\end{tabular}

Fonte: Soluções minimizadoras apresentadas pelos pescadores da colônia Z-2 de Cáceres/MT.

\section{Referências}

BACHELARD, G. A água e os sonhos. 4. ed. Trad. Antonio de Pádua Danesi. São Paulo: Martins Fontes, 2002.

CASTRILLON, S. K. I.; BEZERRA, D. O. S. (Orgs.). Cáceres: uma cidade em busca da sustentabilidade sócio-ambiental. Cáceres: Editora UNEMAT, 2003.

CARVALHO, I. C. M. Em direção ao mundo da vida: interdisciplinaridade e educação ambiental. Brasília: IPÊ, 1998.

CUNHA, L. H. O. Significados múltiplos das águas. In: DIEGUES, A. C. (Org.). A imagem das águas. São Paulo: Hucitec, 2000. p. 15-25.

DAVIES, A.; BLAKELEY, A. G. H.; KIDD, C. Fisiologia humana. Trad. Charles Alfred Esbérard. Porto Alegre: Artmed, 2002.

DEL RIO, V. Cidade da mente, cidade real: percepção ambiental e revitalização na área portuária do RJ. In: OLIVEIRA, L.; DEL RIO, V. (Orgs.). Percepção ambiental: a experiência brasileira. São Paulo: Studio Nobel, 1996. p. 3-22.

DIEGUES, A. C. (Org.). A imagem das águas. São Paulo: Hucitec, 2000.

FERRARA, L. D. As cidades ilegíveis: percepção ambiental e cidadania. In: OLIVEIRA, L.; DEL RIO, V. (Orgs.). Percepção ambiental: a experiência brasileira. São Paulo: Studio Nobel, 1996. p. 61-80.

FORGUS, R. H. Percepção: o processo básico do desenvolvimento cognitivo. Trad. Nilce Pinheiro Miejias. São Paulo: Herder; EDUSP, 1971. 
Bezerra, D. O. S.; Oliveira, H. T.

HOEFFEL, J. L.; FADINI, A. A. B. Percepção ambiental. In: ENCONTROS e caminhos: formação de educadoras(es) ambientais e coletivos educadores. Brasília: MMA, Departamento de Educação Ambiental, 2007. v. 2. p. 253-262.

LABERGE, J. As naturezas do pescador. In: DIEGUES, A. C. (Org.). A imagem das águas. São Paulo: Hucitec, 2000. p. 39-58.

LIMA, A. M. Um estudo com pescadores pantaneiros de Cáceres - Mato Grosso: o rio Paraguai como elemento educativo. 2004. 103f. Dissertação (Mestrado em Educação e Meio Ambiente) - Universidade Federal de Mato Grosso, Cuiabá, 2004.

LOUREIRO, C. F. B. Trajetória e fundamentos da educação ambiental. 2. ed. São Paulo: Cortez, 2006.

LUIZ NETTO, S. Pescadores de barranco das margens do rio Paraguai em Cáceres MT. 2001. 52f. Trabalho de Conclusão de Curso (Graduação) - Universidade do Estado do Mato Grosso, Cáceres, 2001.

Pesca profissional versus pesca esportiva: suas diferenças e semelhanças no Pantanal Mato-grossense, Brasil. 2006. 47f. Dissertação (Mestrado em Ecologia e Conservação da Biodiversidade) - Universidade Federal do Mato Grosso, Cuiabá, 2006.

LYNCH, K. A imagem da cidade. 3. ed. Trad. Jefferson Luiz Camargo. São Paulo: Martins Fontes, 2006.

MACHADO, L. M. C. P. A Serra do Mar paulista: um estudo da paisagem valorizada. 1988. 312f. Tese (Doutorado) - Universidade Estadual Paulista, Instituto de Geociências e Ciências Exatas, Rio Claro, 1988.

MARIN, A. A. Percepção ambiental e imaginário dos moradores do município de Jardim, MS. 2003. 306f. Tese (Doutorado) - Universidade Federal de São Carlos, Centro de Ciências Biológicas e da Saúde, São Carlos, 2003.

MARTINS, C. C. C. A exclusão sócio-econômica provocada pelo turismo na população ribeirinha de Cáceres - MT. 2003. xxxf. Trabalho de Conclusão de Curso (Especialização em Turismo e Desenvolvimento Local e Regional) - Departamento de Geografia, Universidade do Estado do Mato Grosso, Cáceres, 2003.

MEDEIROS, H. Q. Impactos das políticas públicas sobre os pescadores profissionais do pantanal de Cáceres, Mato Grosso. 1999. 217f. Dissertação (Mestrado em Ciência Ambiental) - Instituto de Geociências, Universidade de São Paulo, 1999.

POLTRONIÉRI, L. C. Percepção de custos e riscos provocados pelo uso de praguicidas na agricultura. In: OLIVEIRA, L.; DEL RIO, V. (Org.). Percepção ambiental: a experiência brasileira. São Paulo: Studio Nobel; São Carlos: UFSCar, 1996. p. 237-253.

SAUVÉ, L. Educação ambiental: possibilidades e limitações. Educação e Pesquisa, São Paulo, v. 31, n. 2, p. 317-322, 2005. 
Impactos socioambientais no Rio Paraguai ...

SILVA, A. et al. Avaliação da erosão na margem direita do rio Paraguai a jusante da praia do Julião município de Cáceres-MT. Revista Geográfica Acadêmica, Goiânia, v. 1, n. 1, p. 5-19, 2007.

TONISSI, R. M. T. Percepção e caracterização ambientais da área verde da microbacia do córrego da Água Quente (São Carlos, SP) como etapas de um processo de educação ambiental. 2005. 281f. Tese (Doutorado em Ciências da Engenharia Ambiental) - Escola de Engenharia, Universidade de São Paulo, São Carlos, 2005.

TOZONI-REIS, M. F. C. Temas ambientais como temas geradores: contribuições para uma metodologia educativa ambiental crítica, transformadora e emancipatória. Educar em Revista, Curitiba, v. 9, n. 27, p. 93-110, 2006.

TUAN, Yi-Fu. Topofilia: um estudo da percepção, atitudes e valores do meio ambiente. Trad. Lívia de Oliveira. São Paulo: DIFEL, 1980.

WHYTE, A. V. T. La perception de l'environnement: lignes directrices mèthodologiques pour les études sur le terrain. Paris: Unesco, 1978. (Collection notes techniques du MAB, 5). 